\title{
Evaluation of Cloud Feedback at Local Scale: Warming or Cooling?
}

\author{
Esmaiel Malek \\ Department of Applied Aviation Science, Embry-Riddle Aeronautical University, 600 S. Clyde Morris Boulevard, Daytona Beach, FL \\ 32114-3900, USA
}

\begin{abstract}
Clouds affect the climate by positive and negative feedback. To study these effects at local scale, a radiation station was set up, which used two CM21 Kipp \& Zonen pyranometers (one inverted), and two CG1 Kipp \& Zonen pyrgeometers (one inverted) in Logan, Utah, USA. The pyranometers and pyrgeometers were ventilated using four CV2 Kipp \& Zonen ventilation systems. Ventilation of pyranometers and pyrgeometers prevent dew, frost and snow accumulation, which otherwise would disturb the measurement. Knowing that available energy $\left(\mathrm{R}_{\mathrm{n}}\right)$ as $\mathrm{R}_{\mathrm{n}}=\mathrm{R}_{\mathrm{si}}-\mathrm{R}_{\mathrm{so}}+\mathrm{R}_{\mathrm{li}}-\mathrm{R}_{\mathrm{lo}}$ where $\mathrm{R}_{\mathrm{si}}$ and $\mathrm{R}_{\mathrm{so}}$ are downward and upward solar radiation, respectively, and $R_{l i}$ and $R_{l o}$ as atmospheric and terrestrial, respectively, the effects of cloudiness were evaluated on a daily and annual basis. The results indicate that for the partly cloudy days of 4 and 5 September, 2007, cloudiness caused less available energy $\left(R_{n}\right)$ in the amounts of $-1.83 \mathrm{MJ} \cdot \mathrm{m}^{-2} \cdot \mathrm{d}^{-1}$ and $-3.83 \mathrm{MJ} \cdot \mathrm{m}^{-2} \cdot \mathrm{d}^{-1}$ on these days, respectively. As shown, due to cloudiness at the experimental site, the net radiation loss was $2,804-4,055=-1,251 \mathrm{MJ} \cdot \mathrm{m}^{-2} \cdot \mathrm{y}^{-1}$, which indicates a negative feedback due to cloudiness.
\end{abstract}

Key words: Cloud feedback, pyranometer, pyrgeometer.

\section{Introduction}

Clouds are large collections of very tiny droplets of water or ice crystals. The droplets are so small and light that they can float in the air. Cloud feedback is the coupling between cloudiness and surface air temperature in which as the surface air temperature changes the volume of clouds change, which could then amplify or diminish the initial temperature perturbation. The increased cloud thickness or extent of cloudiness could reduce incoming solar radiation and limit warming, at the same time, emit additional long wave radiation in the waveband which the atmospheric gaseous emission lacks (from 8-13 $\mu \mathrm{m}$ ). The effect of clouds on the radiation balance of the Earth (cloud forcing) is that, on the average the mean surface temperature decrease. When the climate system is disturbed, the cloud forcing may change and this change will exert a feedback on the system.

Corresponding author: Esmaiel Malek, Ph.D., main research filed: meteorology. E-mail: maleke@erau.edu.
Climate models predict that clouds will have an overall positive feedback effect, that is, their presence will tend to enhance any surface-temperature changes, as in the greenhouse effect [1].

Clouds are much too small to be modeled explicitly in a global simulation, and the physical processes involved in clouds are still imperfectly understood, but clouds and their radiative effects are too important to be ignored. It is necessary to parameterize these effects [2]. Many scientists have worked on the concept of cloud feedback. Among them are: Wetherald, R. T. [3] have worked on the influence of the cloud feedback upon the sensitivity of climate by comparing the behavior of two various climate models with predicted and prescribed cloud cover. Soden, B. I. $[4,5]$ has described uncertainty in cloud feedback as the leading cause of discrepancy in model prediction of climate change using two versions of atmospheric models. Sun, M. [6] has evaluated feedback mechanisms in coupled atmosphere/ocean climate models. Zhang M. [7] investigated the physical 
mechanism of low cloud feedback in the Community Atmospheric Model (CAM) through idealized Single-Column Model (SCM) experiments over the subtropical eastern oceans and reported the degree of thermodynamic and dynamic effects on the negative cloud feedback in the model. There is little information about evaluation of clouds effect on the radiation budget components and their feedback at the local scale. To address this concern, Malek, E. evaluated appropriate equations for computation of cloudless atmospheric emissivity and proposed an algorithm for a ground-based approach to parameterize clouds at local scale $[8,9]$. The present article deals with the evaluation of clouds on the radiation budget components and their feedback at the local scale.

\section{Instrumentations}

This experimental site is located at the Cache Airport in Logan $\left(41^{\circ} 47^{\prime} \mathrm{N}, 111^{\circ} 51^{\prime} \mathrm{W}, 1,460 \mathrm{~m}\right.$ above $\mathrm{msl}$ ), situated in the middle of a mountainous valley,
Utah, USA, since October, 1995. To evaluate the cloud feedback at local scale, a radiation station was set up, which used two CM21 Kipp \& Zonen pyranometers (one inverted), and two CG1 Kipp \& Zonen pyrgeometers (one inverted) in Logan, Utah, U.S.A. The pyranometers and pyrgeometers were ventilated using four CV2 Kipp \& Zonen ventilation systems. Ventilation of pyranometers and pyrgeometers prevents dew, frost and snow accumulation, which otherwise would disturb the measurement.

All sensors were installed at about 3-m above the ground. Fig. 1 shows pyranometers, pyrgeometers and a non-ventilated net radiometer $\left(Q^{*} 7.1\right.$ net radiometer, Radiation energy Balance System, Inc. (REBS)) along with other sensors at the experimental site [9].

\section{Methodology}

The available energy $\left(\mathrm{R}_{\mathrm{n}}\right)$ during any sky conditions for the experimental site can be expressed as in Eq. (1):

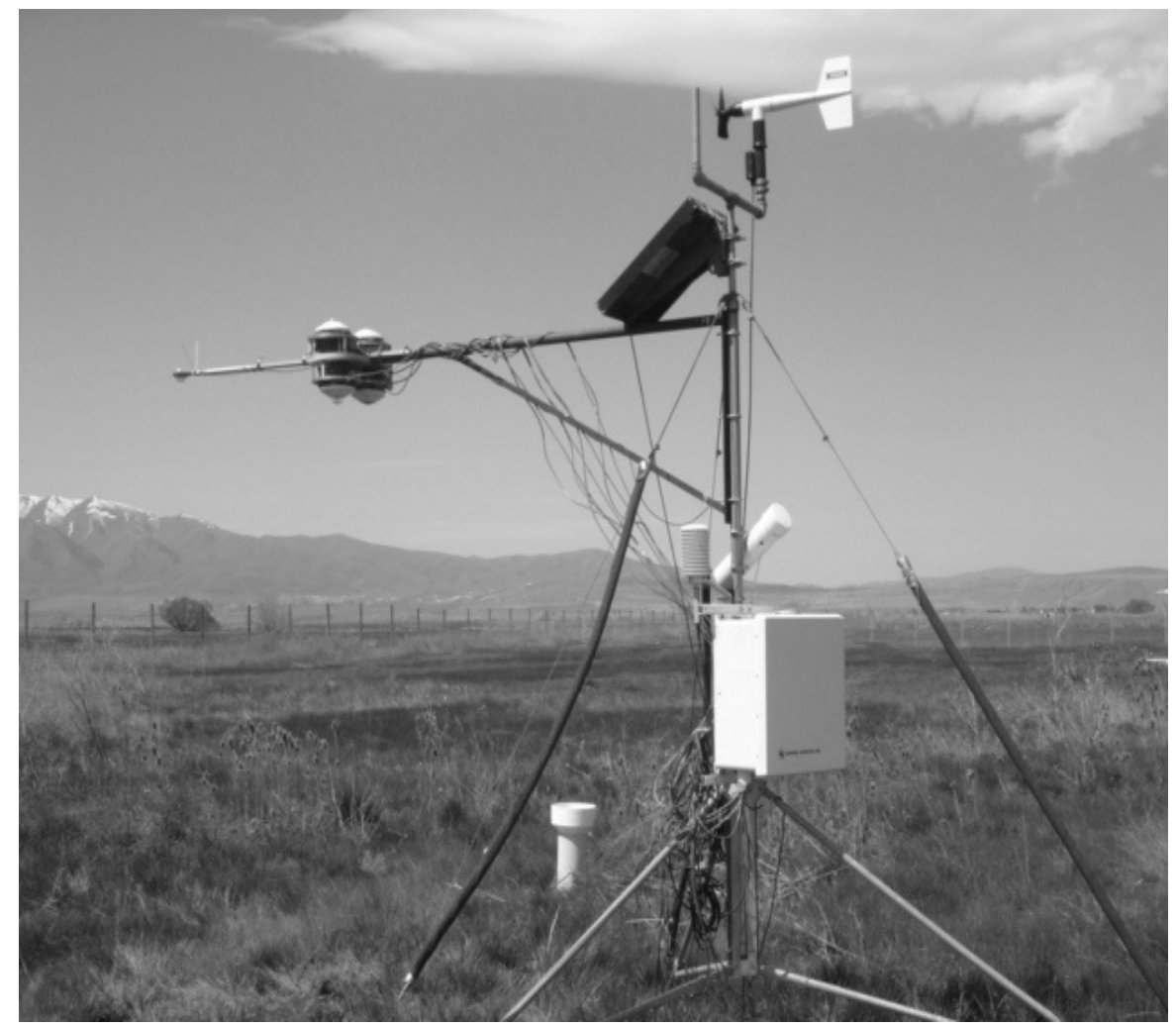

Fig. 1 Pyranometers, pyrgeometers and a non-ventilated net radiometer ( $Q * 7.1$ net radiometer) at the experimental site in Logan, Utah, USA. 


$$
\mathrm{R}_{\mathrm{n}}=\mathrm{R}_{\mathrm{si}}-\mathrm{R}_{\mathrm{so}}-\mathrm{R}_{\mathrm{lo}}+\mathrm{R}_{\mathrm{li}}
$$

Where, $R_{\mathrm{si}}$ and $\mathrm{R}_{\mathrm{so}}$ are downward and upward solar (shortwave) radiation, respectively; and $\mathrm{R}_{\mathrm{li}}$ and $\mathrm{R}_{\mathrm{lo}}$ are the downward atmospheric and upward terrestrial (longwave) radiation, respectively. All energy terms in Eq. (1) are in $\mathrm{W} \cdot \mathrm{m}^{-2}$ or $\mathrm{MJ} \cdot \mathrm{m}^{-2} \cdot \mathrm{d}^{-1}$. Below are approaches to evaluate the radiation budget components during cloudless and cloudy sky conditions.

\subsection{Cloudless Skies}

Allen, R. G. and Monteith, J. L. [10, 11] described approaches for computation of the daily and shorter periods of extra-terrestrial $\left(R_{a}\right)$, cloudless downward solar $\left(\mathrm{R}_{\mathrm{si}}\right)$, and cloudless net upward terrestrial $\left(\mathrm{R}_{\mathrm{nl}}=\right.$ $\mathrm{R}_{\mathrm{lo}}-\mathrm{Rl}_{\mathrm{i}}$ ) radiation. Brunt, D., Brutsaert, W. H., Idso, S. B., and Monteith, J. L. [12-15] proposed approaches for computation of cloudless atmospheric emissivity using the 2-m air temperature and moisture. Malek, E. [8] compared these approaches and computated cloudless $\mathrm{R}_{\mathrm{li}}$ according to the reference 14 .

The 20-min and daily $R_{a}$, and cloudless $R_{s i}, R_{s o}, R_{l i}$ and $R_{\text {lo }}$ radiation was evaluated during the years 1996 through 2007 at this mountainous experimental site. Using the linear regression, relationship between the daily and shorter period $R_{a}$ and cloudless $R_{s i}$ was developed throughout 1996-2007. Results showed that about $73 \%$ of extra-terrestrial was measured at the surface during cloudless days of the above-mentioned period (an atmospheric transmissivity of $73 \%$ ) and the cloudless albedo is about $18 \%$ in average.

\subsection{Cloudy Skies}

Prediction of cloud amount $\left(\mathrm{A}_{\mathrm{c}}\right)$ and cloud height $\left(\mathrm{H}_{\mathrm{c}}\right)$ is of great importance to climate modeling. Comparing the downward atmospheric radiation measured by the pyrgeometer $\left(\mathrm{R}_{\text {lim }}\right)$ for any sky conditions (cloudless or cloudy) with the calculated one for cloudless skies $\left(\mathrm{R}_{\text {lic }}\right)$ yields [9]:

$$
\mathrm{A}_{\mathrm{c}}=\left(\mathrm{R}_{\text {lim }}-\mathrm{R}_{\text {lic }}\right) /\left(\left(1-\varepsilon_{\mathrm{ac}}\right) * \sigma * \mathrm{~T}_{\mathrm{c}} 4\right)
$$

Where, $A_{c}$ (from zero for cloudless skies to one for overcast skies), $\mathrm{T}_{\mathrm{c}}$ and $\varepsilon_{\mathrm{ac}}$ are the cloud amount (cloudiness), the cloud base temperature, and cloudless atmospheric emissivity, respectively. Whenever, $R_{\text {lim }}$ is almost equal to $R_{\text {lic }}$, this implies a cloudless sky. When $\mathrm{R}_{\text {lim }}>\mathrm{R}_{\text {lic }}$, the sky conditions could be from partly cloudy to overcast. $\varepsilon_{\mathrm{ac}}$ is related to the 2-m air temperature and moisture. Cloudiness can be evaluated by an algorithm developed by [9].

\section{Results and Discussion}

To evaluate the daily cloud contribution to the radiation budget components at the local scale, the period of 4-5 September, 2007, was chosen. Fig. 2 shows the 20-min values of extra-terrestrial radiation $\left(\mathrm{R}_{\mathrm{a}}\right)$, the cloudless and measured downward solar radiation $\left(\mathrm{R}_{\mathrm{si}}\right)$, and cloudiness on partially cloudy days of 4 and 5 September, 2007.

As shown in Fig. 2, the downward solar radiation loss (measured-cloudless) was $15.30-23.94=$ $-8.64 \mathrm{MJ} /\left(\mathrm{m}^{2} \cdot \mathrm{d}\right)$ and $14.94-23.17=-8.23$ $\mathrm{MJ} /\left(\mathrm{m}^{2} \cdot \mathrm{d}\right)$ on 4 and 5 September, 2007, respectively. The cloudless and cloudy upward solar radiation on 4 and 5 September, 2007 are presented Fig. 3. As shown in Fig. 3, due to cloudiness, less solar radiation was reflected back to the sky, which means a gain of upward solar radiation compared to cloudless conditions: gain $=$ cloudless - measured $=4.19-$ $2.87=1.32 \mathrm{MJ} /\left(\mathrm{m}^{2} \cdot \mathrm{d}\right)$ and $4.15-2.62=1.53$ $\mathrm{MJ} /\left(\mathrm{m}^{2} \cdot \mathrm{d}\right)$ on 4 and 5 September, 2007 , respectively.

The 20-min values of measured and cloudless downward atmospheric radiation and cloudiness on 4 and 5 September, 2007, are presented in Fig. 4. As depicted in this figure, the measured and computed atmospheric radiation were identical during cloudless periods, but, due to cloudiness, measured atmospheric radiation was greater than the cloudless one on these 2 days which amounted to (measured - cloudless) $=$ $35.28-32.36=2.92 \mathrm{MJ} /\left(\mathrm{m}^{2} \cdot \mathrm{d}\right)$ and $33.36-$ $31.78=1.58 \mathrm{MJ} /\left(\mathrm{m}^{2} \cdot \mathrm{d}\right)$ on 4 and 5 September, 2007, respectively.

The effects of cloudiness on the upward terrestrial radiation on 4-5 September, 2007, are shown in Fig. 5. 
4-5 September, 2007

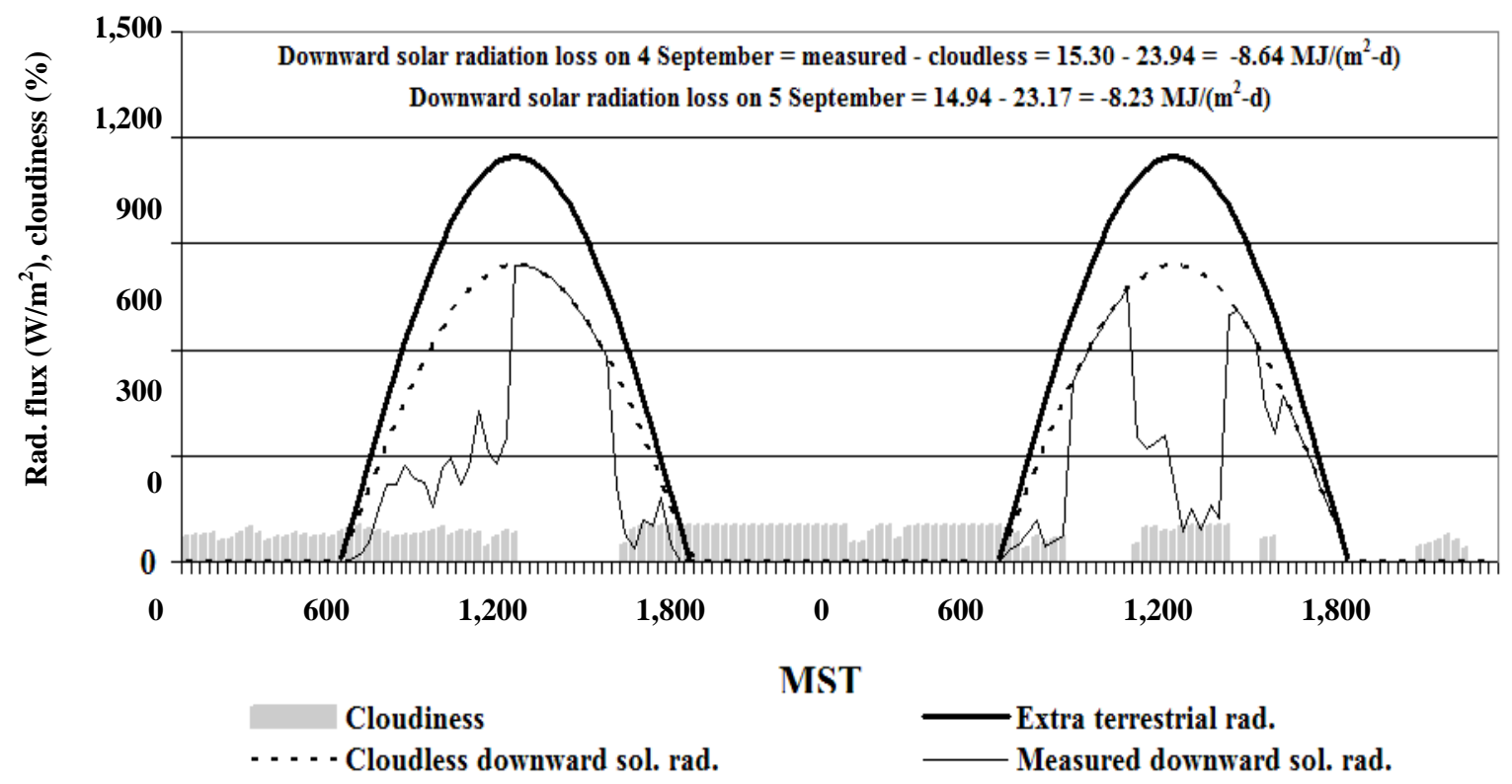

Fig. 2 The 20-min values of extra-terrestrial radiation $\left(R_{a}\right)$, the cloudless and the measured downward solar radiation ( $\left.R_{s i}\right)$, and cloudiness on partially cloudy days of 4 and 5 September, 2007, at the experimental site in Logan, Utah, USA.

\section{4-5 September, 2007}

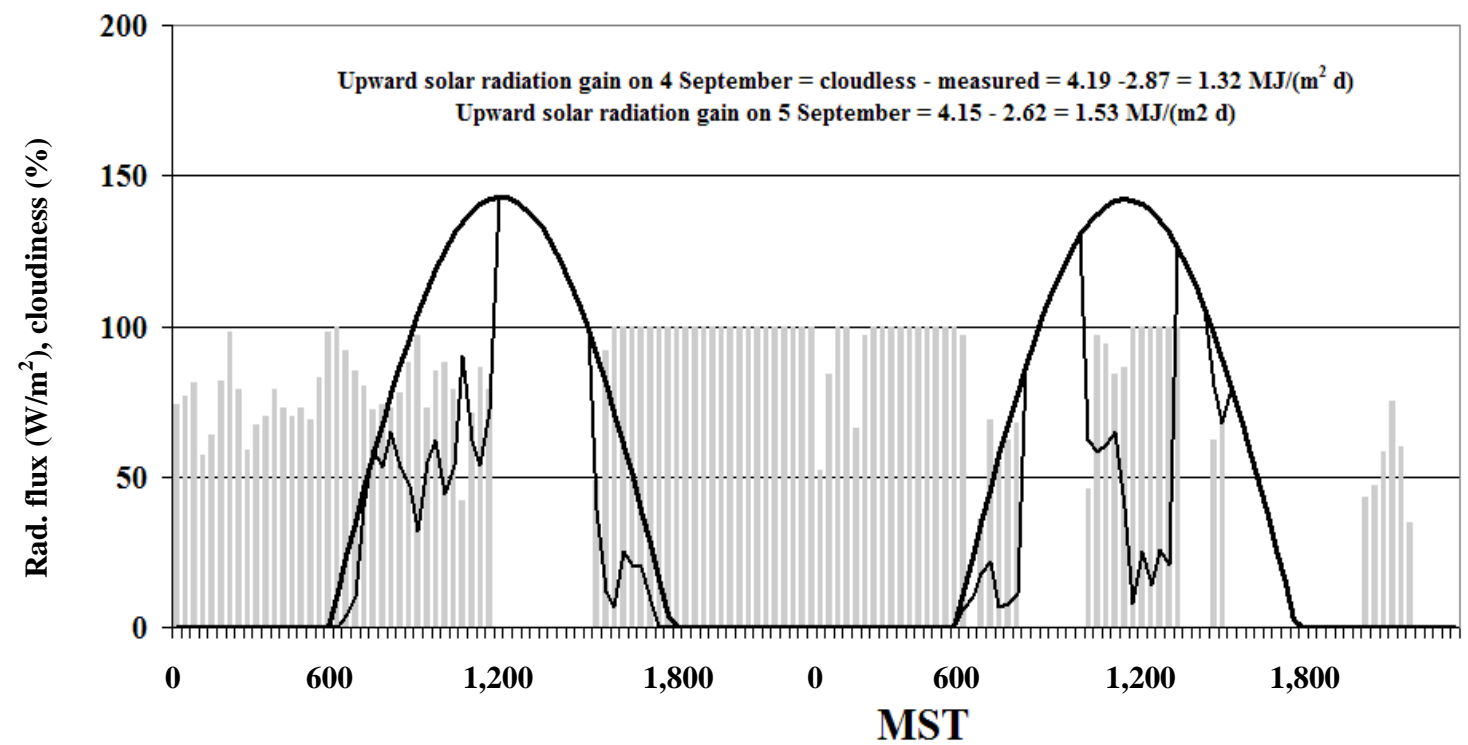

Cloudiness Cloudless upward sol. rad. - Measured upward sol. rad.

Fig. 3 The 20 -min values of the cloudless and measured upward solar radiation $\left(R_{\text {so }}\right)$, and cloudiness on partially cloudy days of 4 and 5 September, 2007, at the experimental site in Logan, Utah, USA. 


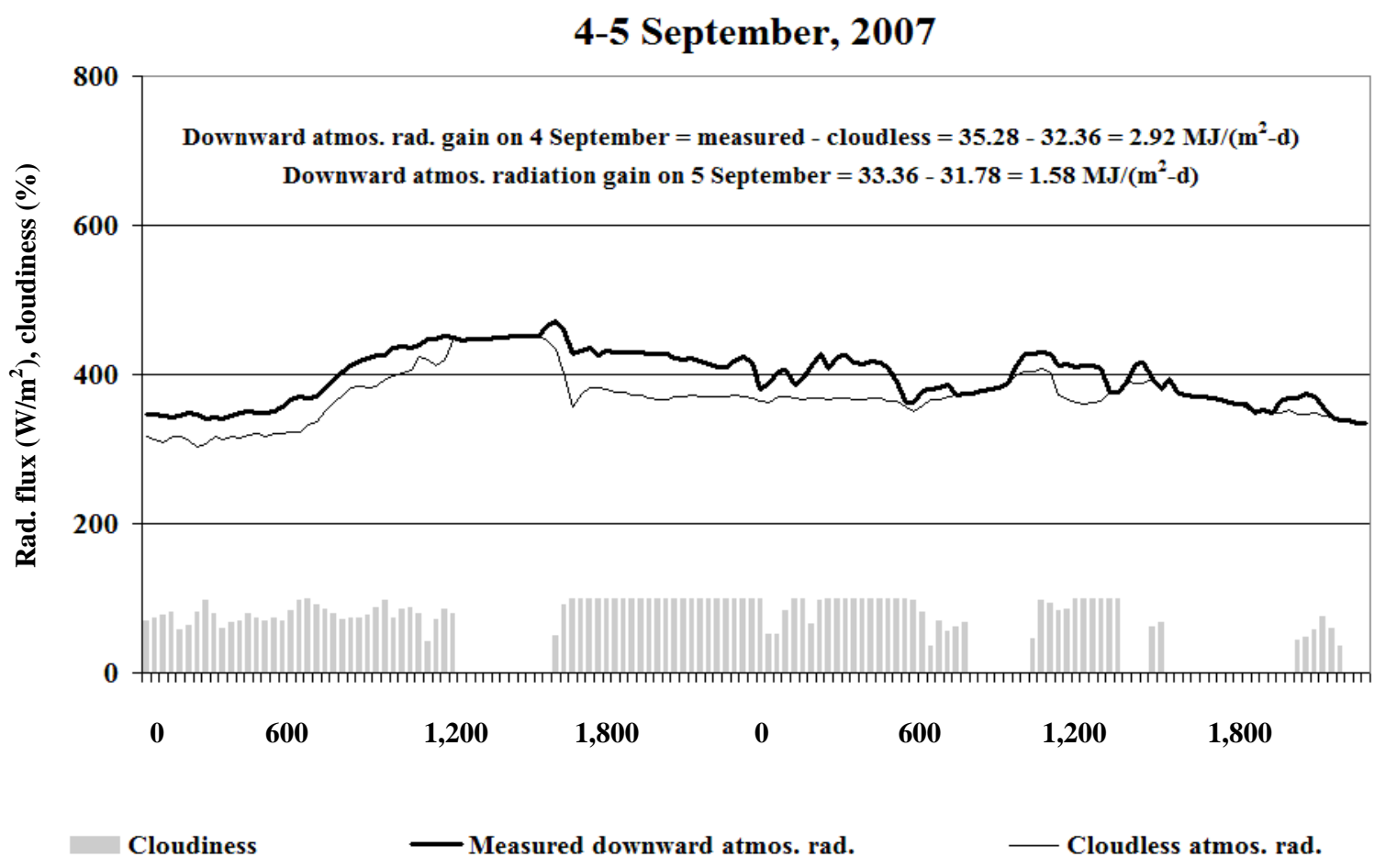

Fig. 4 The 20-min values of measured and cloudless downward atmospheric radiation and cloudiness on 4 and 5 September, 2007, at the experimental site in Logan, Utah, USA.

\section{4-5 September, 2007}

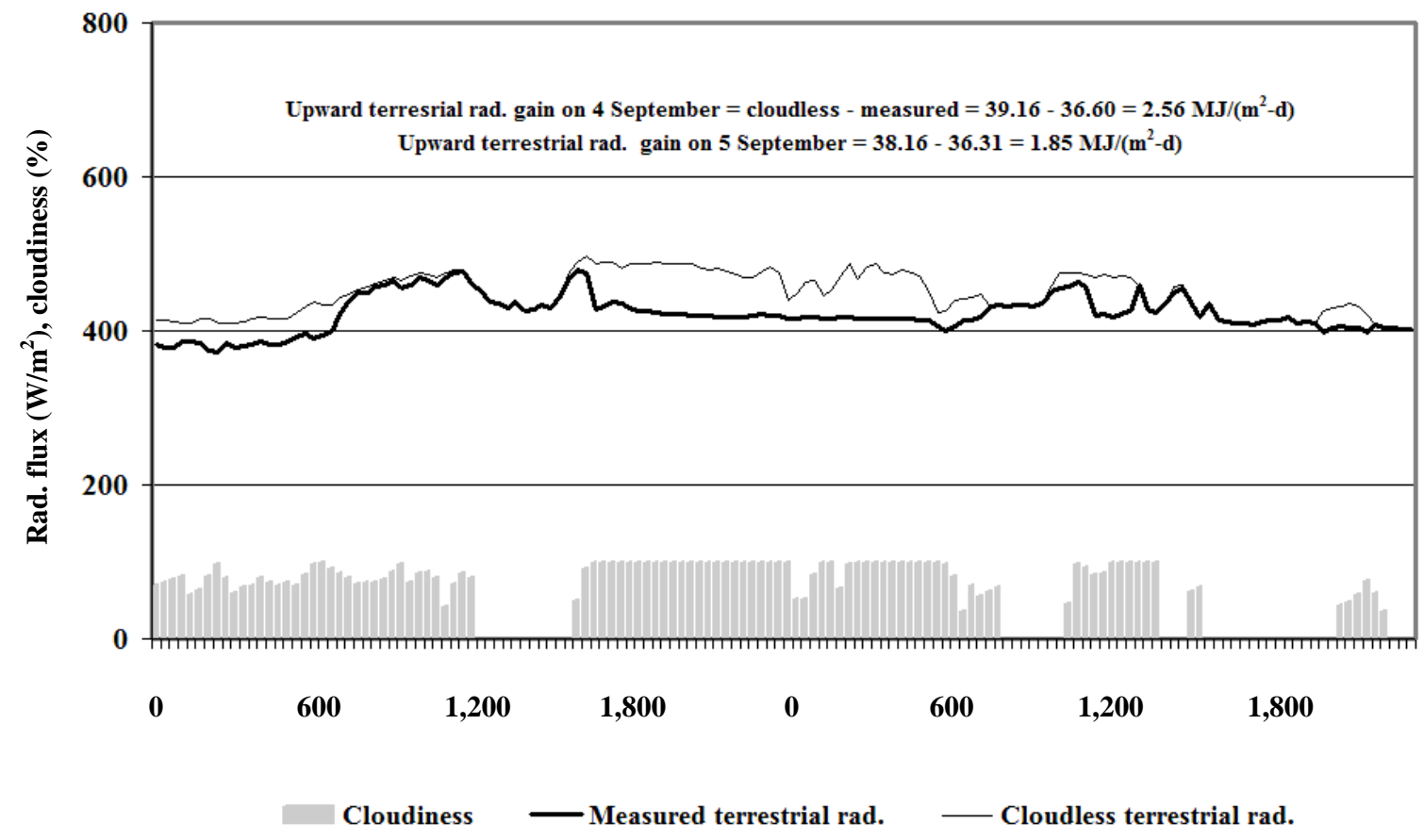

Fig. 5 The 20-min values of measured and cloudless upward terrestrial radiation and cloudiness on 4 and 5 September, 2007, at the experimental site in Logan, Utah, USA. 
Results show less upward terrestrial radiation on these 2 days as: upward terrestrial radiation gain $=39.16-$ $36.60=2.56 \mathrm{MJ} /\left(\mathrm{m}^{2} \cdot \mathrm{d}\right)$ on 4 September and $39.19-$ $36.64=2.55 \mathrm{MJ} /\left(\mathrm{m}^{2} \cdot \mathrm{d}\right)$ on 5 September, 2007.

The radiation balance $\left(\mathrm{R}_{\mathrm{n}}\right)$ and cloudiness for these 2 days are depicted in Fig. 6. As shown in Fig. 6, the daytime cooling (less $\mathrm{R}_{\mathrm{n}}$ ) is due to absorption of less downward solar radiation during cloudy periods and the nighttime warming during cloudy periods is due to absorption of more downward atmospheric radiation.

As shown, net radiation $=$ cloudless - measured $=$ $11.11-12.94=-1.83 \mathrm{MJ} /\left(\mathrm{m}^{2} \cdot \mathrm{d}\right)$ on 4 September and $=9.36-13.19=-3.83 \mathrm{MJ} /\left(\mathrm{m}^{2} \cdot \mathrm{d}\right)$ on 5 September, 2007. The average $24-\mathrm{h}$ values of $2-\mathrm{m}$ air temperature, 2-m relative humidity, and daily precipitation throughout the 2007 are presented in Fig. 7. The cold seasons' precipitation was mainly in the form of snow, which caused higher albedo. Having the 2-m air temperature and humidity and using the proposed algorithm [8,9], the average 24-h cloudiness was evaluated during 2007. Fig. 8 shows the 24-h cloudiness in Logan during 2007.

The cloud-base height in this mountainous valley during 2007 (Fig. 9) ranged from almost zero (fog) up to about 4,200 m. As depicted in Fig. 9, low clouds (up 2,000 m) dominated the area most of the time during the year 2007. Degree of cloudiness and type of precipitation (rain or snow) affects the 24-h values of radiation budget components. The 24-h extra-terrestrial radiation $\left(\mathrm{R}_{\mathrm{a}}\right)$, cloudless and measured incoming solar radiation during the year 2007 in Logan is shown in Fig. 10.

As depicted in Fig. 10, due to cloudiness, the incoming solar radiation was reduced in the amount of (measured - cloudless $)=5,979-7,335=-1,356$ $\mathrm{MJ} /\left(\mathrm{m}^{2} \cdot \mathrm{y}\right)$ during 2007 . The effects of cloudiness on the upward solar radiation during 2007 are presented in Fig. 11. Due to higher albedo during the cold seasons, more solar radiation was lost compared to the cloudless conditions: (cloudless - measured) upward solar radiation loss $=1,284-1,455=-171$ $\mathrm{MJ} /\left(\mathrm{m}^{2} \cdot \mathrm{y}\right)$.

\section{4-5 September, 2007}

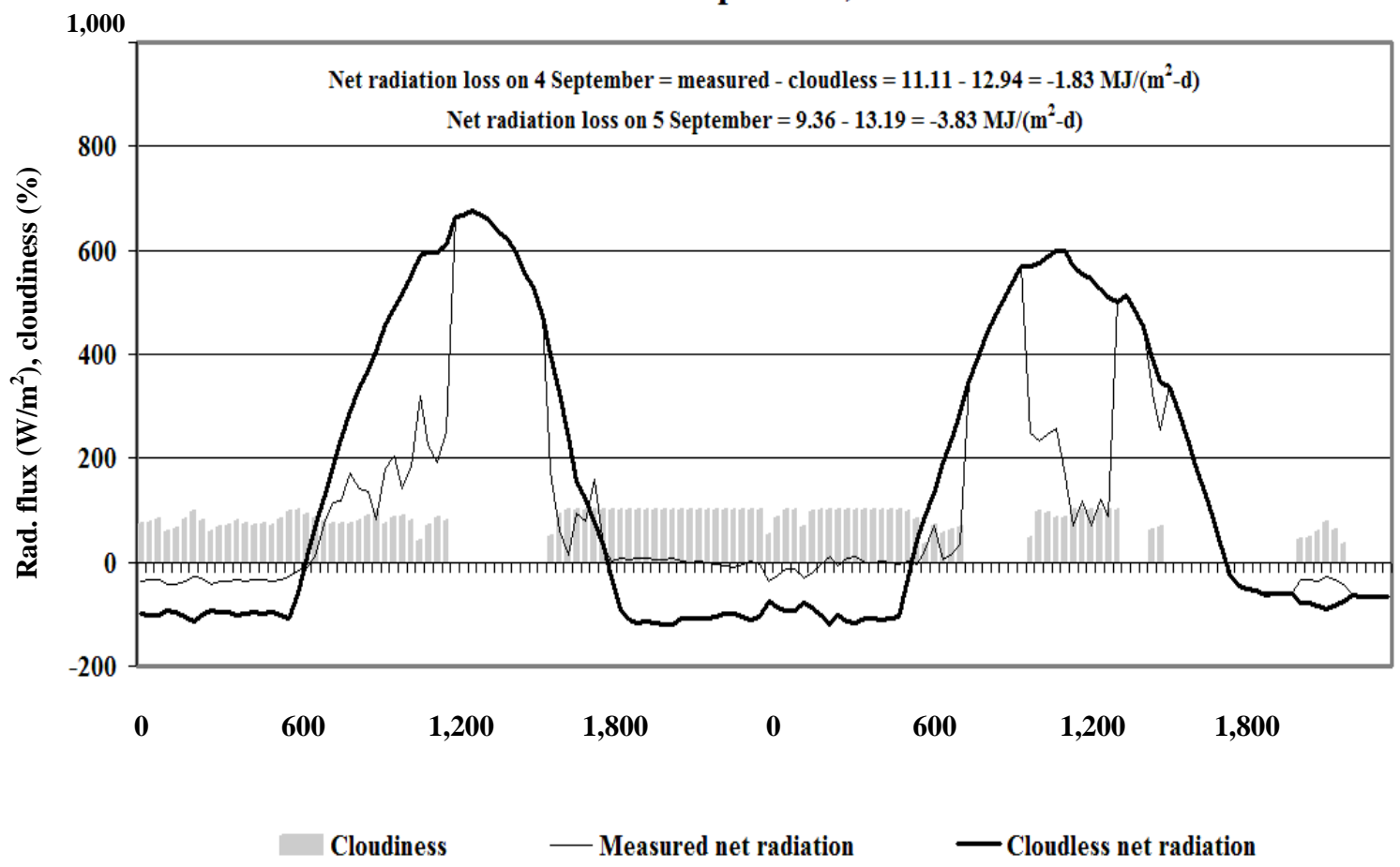

Fig. 6 The 20-min values of measured and cloudless available energy $\left(R_{n}\right)$ and cloudiness on 4 and 5 September, 2007, at the experimental site in Logan, Utah, USA. 
Logan, Utah, USA, 2007

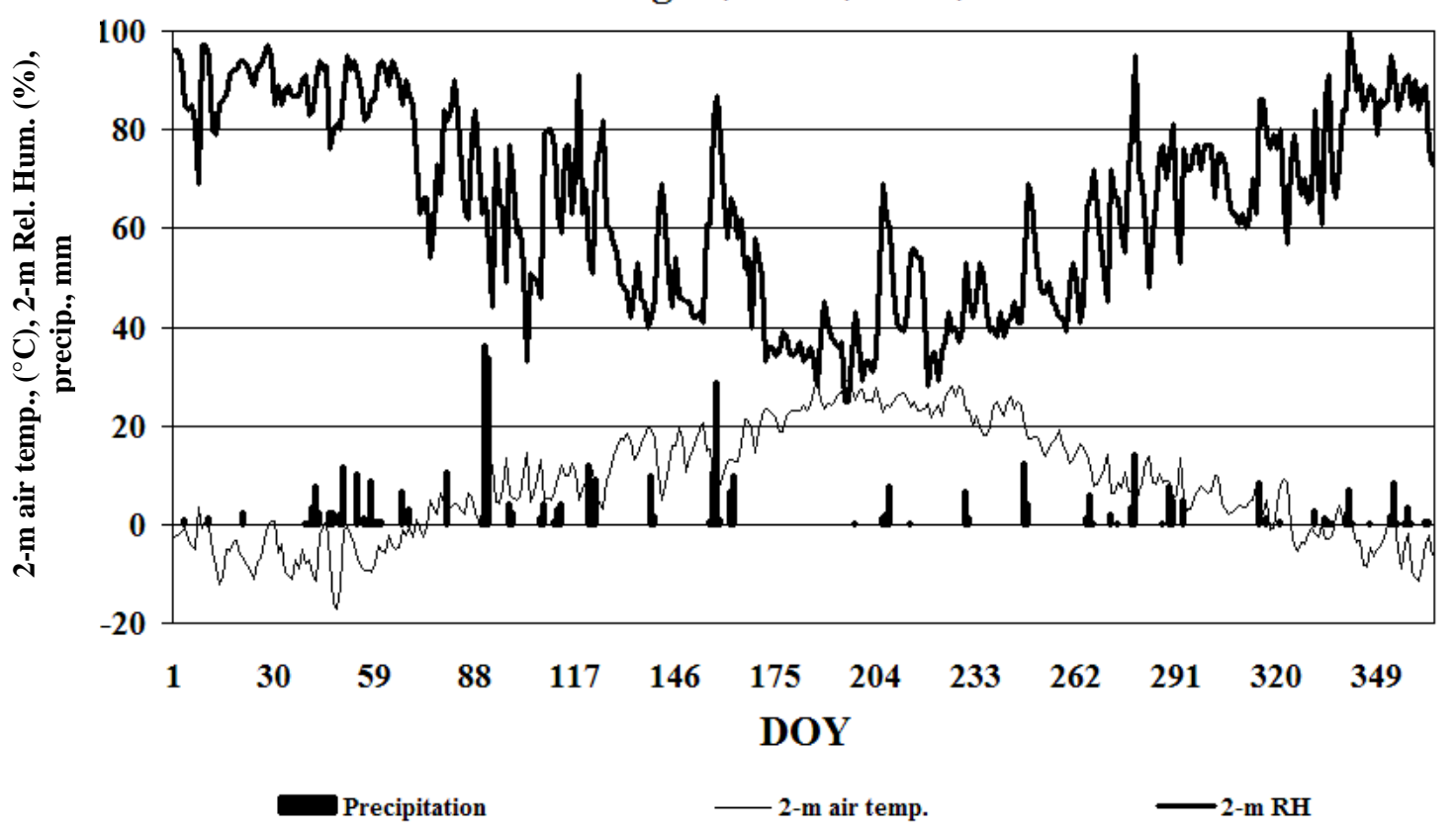

Fig. 7 The average 24-h values of the 2-m air temperature, the 2-m relative humidity, and the daily precipitation during 2007 at the experimental site in Logan, Utah, USA.

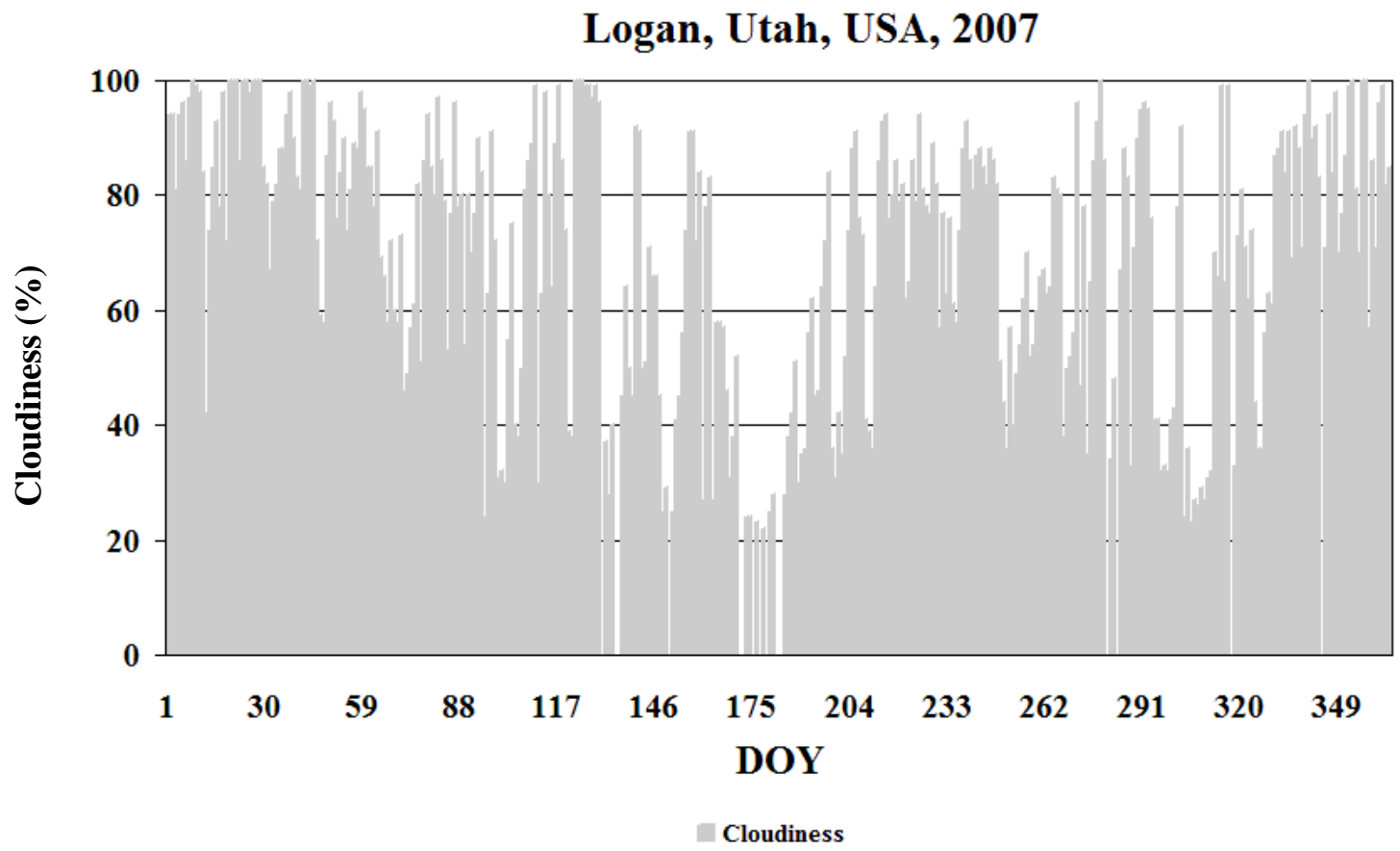

Fig. 8 The average 24-h cloudiness during 2007 at the experimental site in Logan, Utah, USA. 


\section{Logan, Utah, USA, 2007}

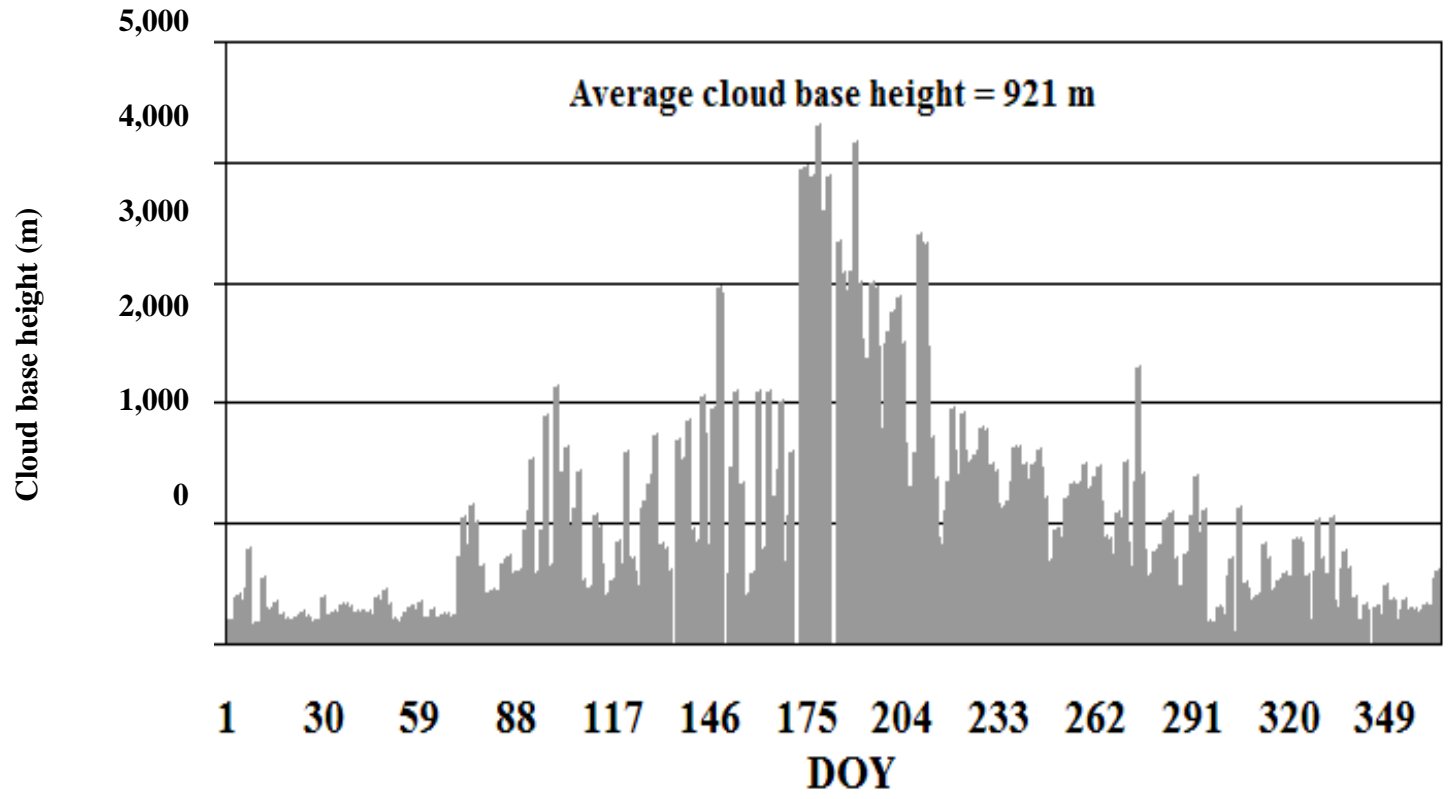

Fig. 9 The cloud-base height variations during 2007 at the experimental site in Logan, Utah, USA.

\section{Logan, Utah, USA, 2007}

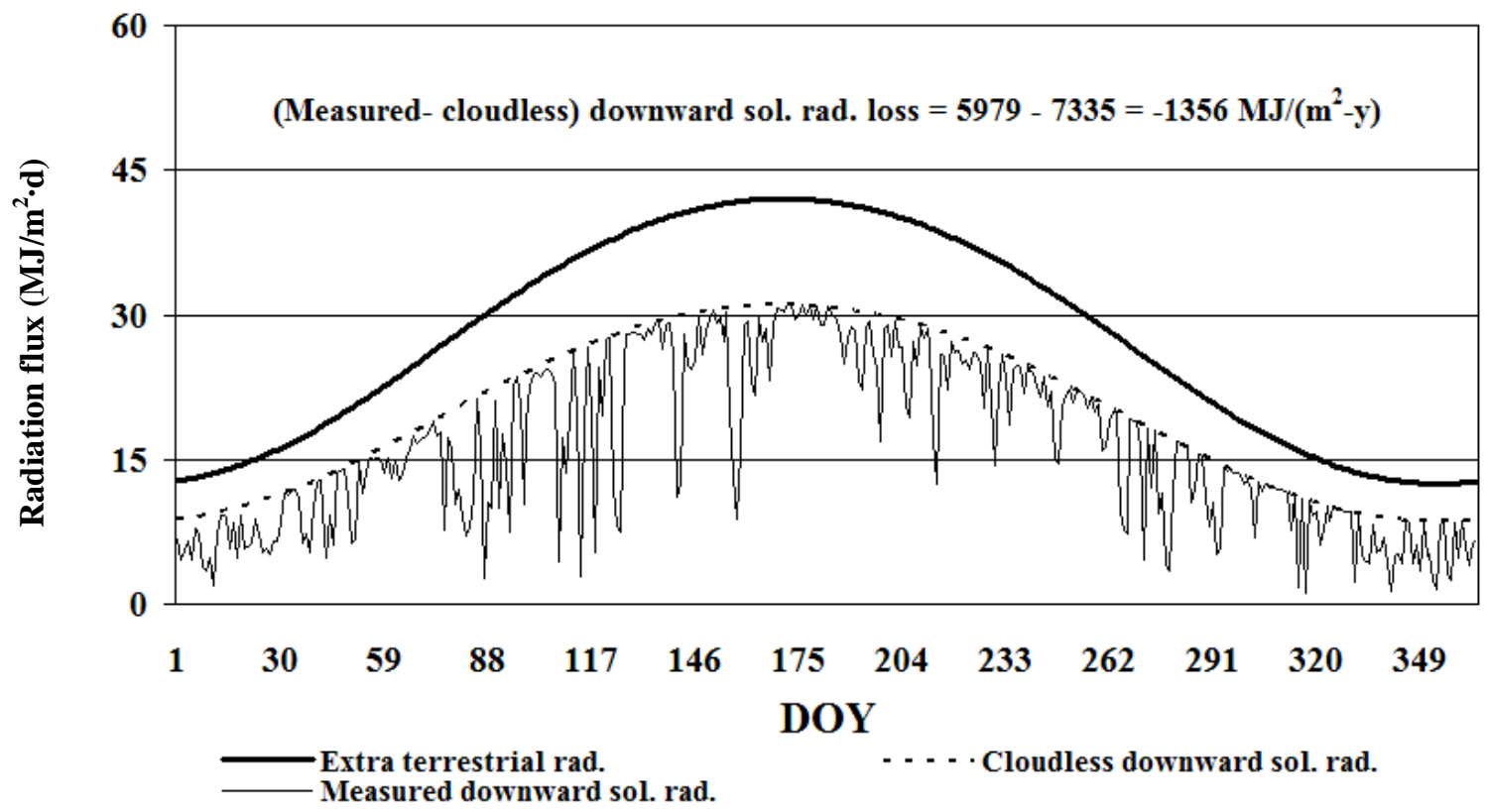

Fig. 10 The 24-h values of extra-terrestrial radiation $\left(R_{\mathrm{a}}\right)$, the cloudless and the measured downward solar radiation $\left(R_{\mathrm{s}}\right)$ during 2007 at the experimental site in Logan, Utah, USA. 
Logan, Utah, USA, 2007

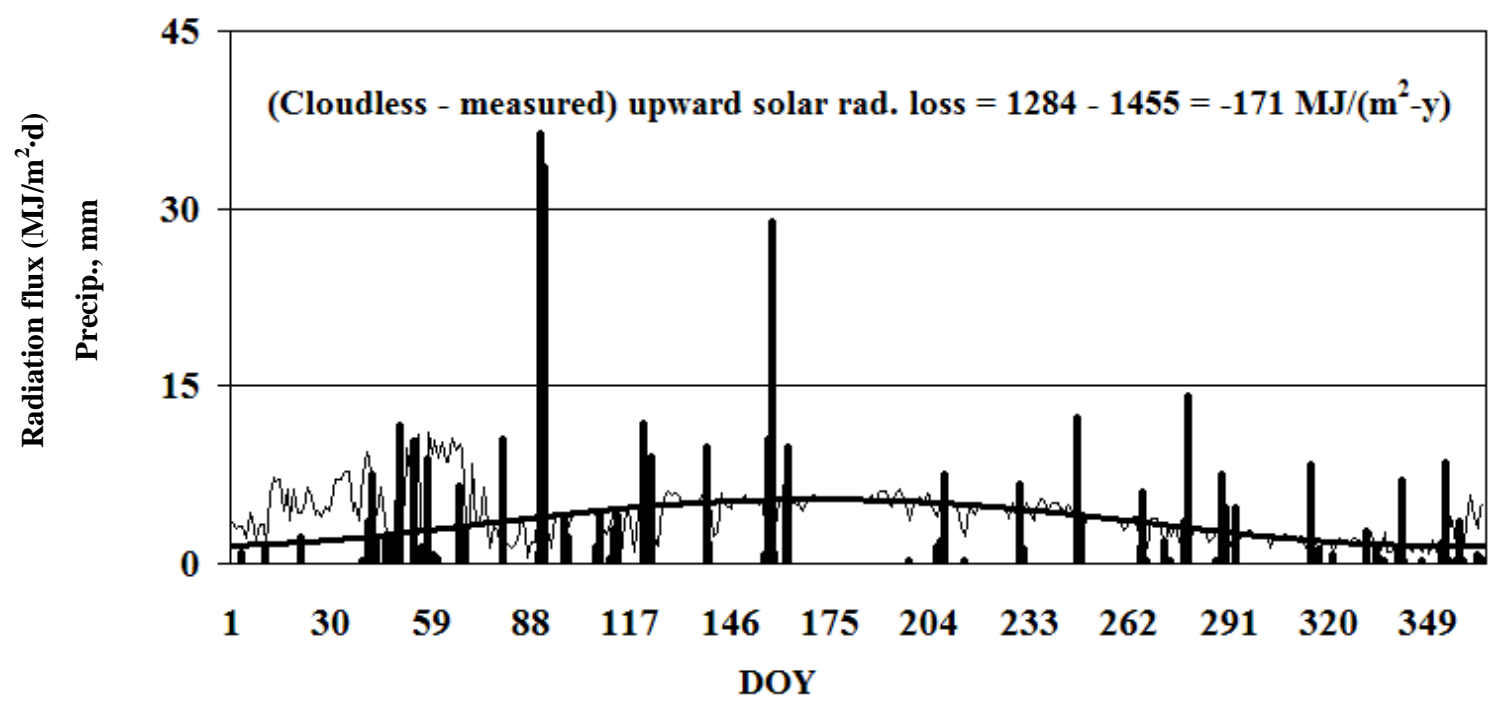

Precipitation

Measured upward sol. rad.

- Cloudless upward sol. rad.

Fig. 11 The 24-h values of the cloudless and measured outgoing solar radiation $\left(R_{s o}\right)$ during 2007 at the experimental site in Logan, Utah, USA.

Logan, Utah, USA, 2007

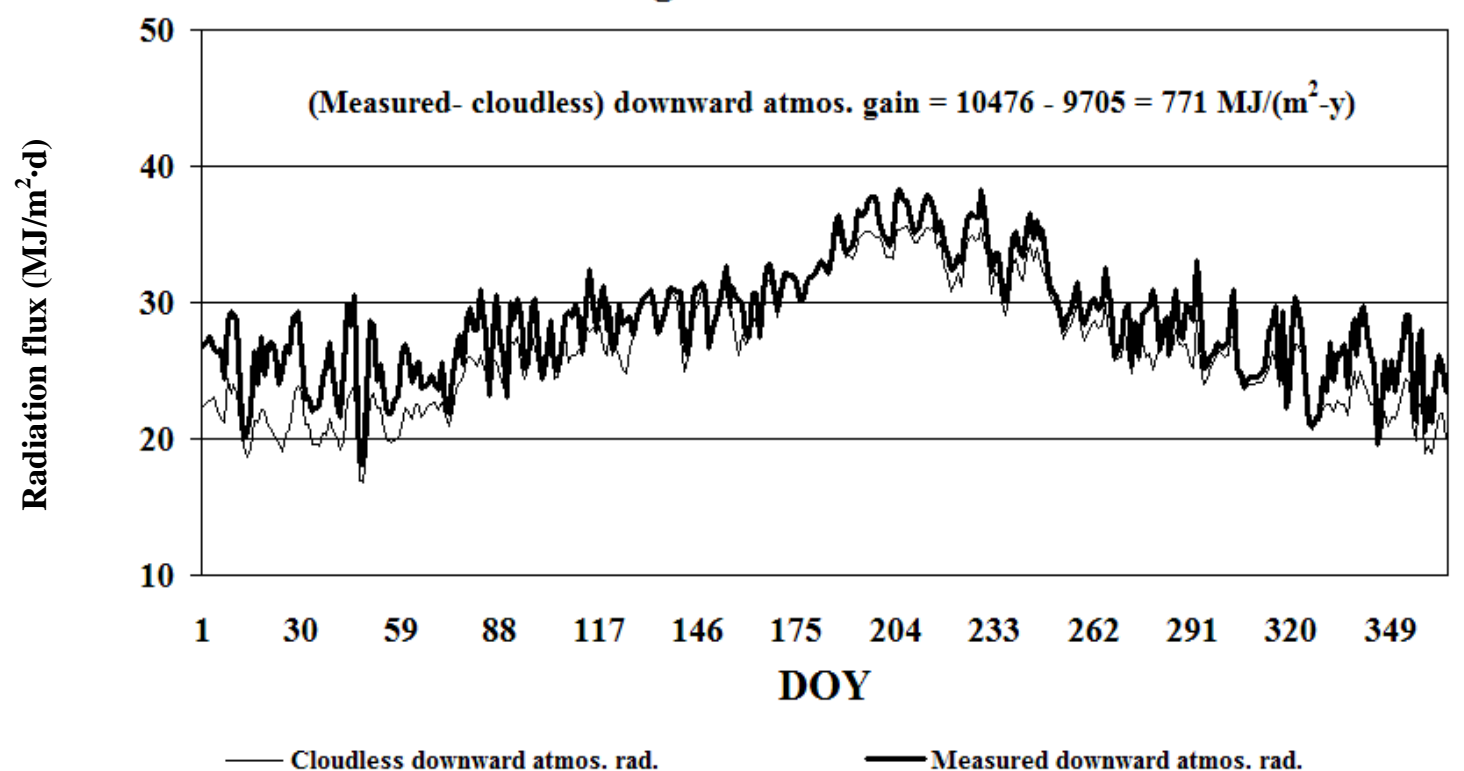

Fig. 12 The 24-h measured and cloudless distribution of downward atmospheric $\left(R_{\mathrm{li}}\right)$ radiation during 2007 at the experimental site in Logan, Utah, USA.

The 24-h measured and cloudless downward atmospheric $\left(\mathrm{R}_{\mathrm{li}}\right)$ and upward terrestrial $\left(\mathrm{R}_{\mathrm{lo}}\right)$ radiation during 2007 in Logan are presented in Fig. 12. As indicated in Fig. 12, more $\mathrm{R}_{\mathrm{li}}$ was received, which means a downward atmospheric radiation (measured
- cloudless) gain $=10,476-9,705=771 \mathrm{MJ} /$ $\left(\mathrm{m}^{2} \cdot \mathrm{y}\right)$. This is due to additional longwave radiation in the waveband (from 8-13 $\mu \mathrm{m}$ ) during cloudy sky which the cloudless sky atmospheric gaseous emission lacks. The cloudless and measured upward terrestrial 
radiation $\left(\mathrm{R}_{\mathrm{lo}}\right)$ during 2007 in Logan is presented in Fig. 13. The higher measured $R_{\text {lo }}$ in mid-summer is due to higher surface temperature. As shown, more $\mathrm{R}_{\mathrm{li}}$ was emitted back, then (cloudless-measured) upward terrestrial radiation loss $=11,702-12,195=-493$ $\mathrm{MJ} /\left(\mathrm{m}^{2} \cdot \mathrm{y}\right)$. The overall effects of cloudiness on the available energy $\left(\mathrm{R}_{\mathrm{n}}\right)$ during 2007 in Logan are presented in Fig. 14. Results indicated that the measured $\mathrm{R}_{\mathrm{n}}=\mathrm{R}_{\mathrm{si}}-\mathrm{R}_{\mathrm{so}}+\mathrm{R}_{\mathrm{li}}-\mathrm{R}_{\mathrm{lo}}$ (for all sky conditions) was less compared to the cloudiness one during 2007 in Logan, then (measured - cloudless) net radiation loss $=2,804-4,055=-1,251 \mathrm{MJ} /\left(\mathrm{m}^{2} \cdot \mathrm{y}\right)$.

Logan, Utah, USA, 2007

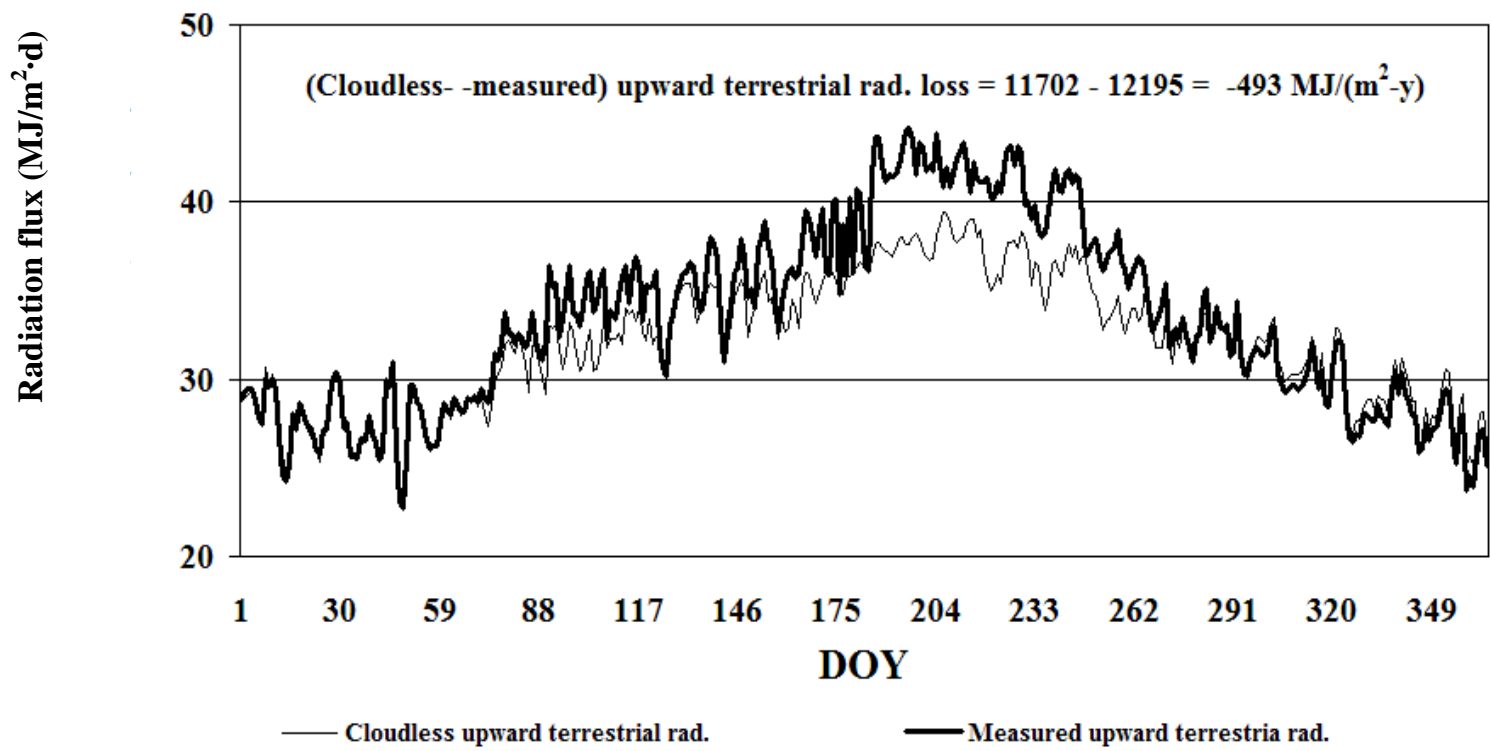

Fig. 13 The cloudless and measured upward terrestrial radiation $\left(R_{l 0}\right)$ during 2007 at the experimental site in Logan, Utah, USA.

Logan, Utah, USA, 2003

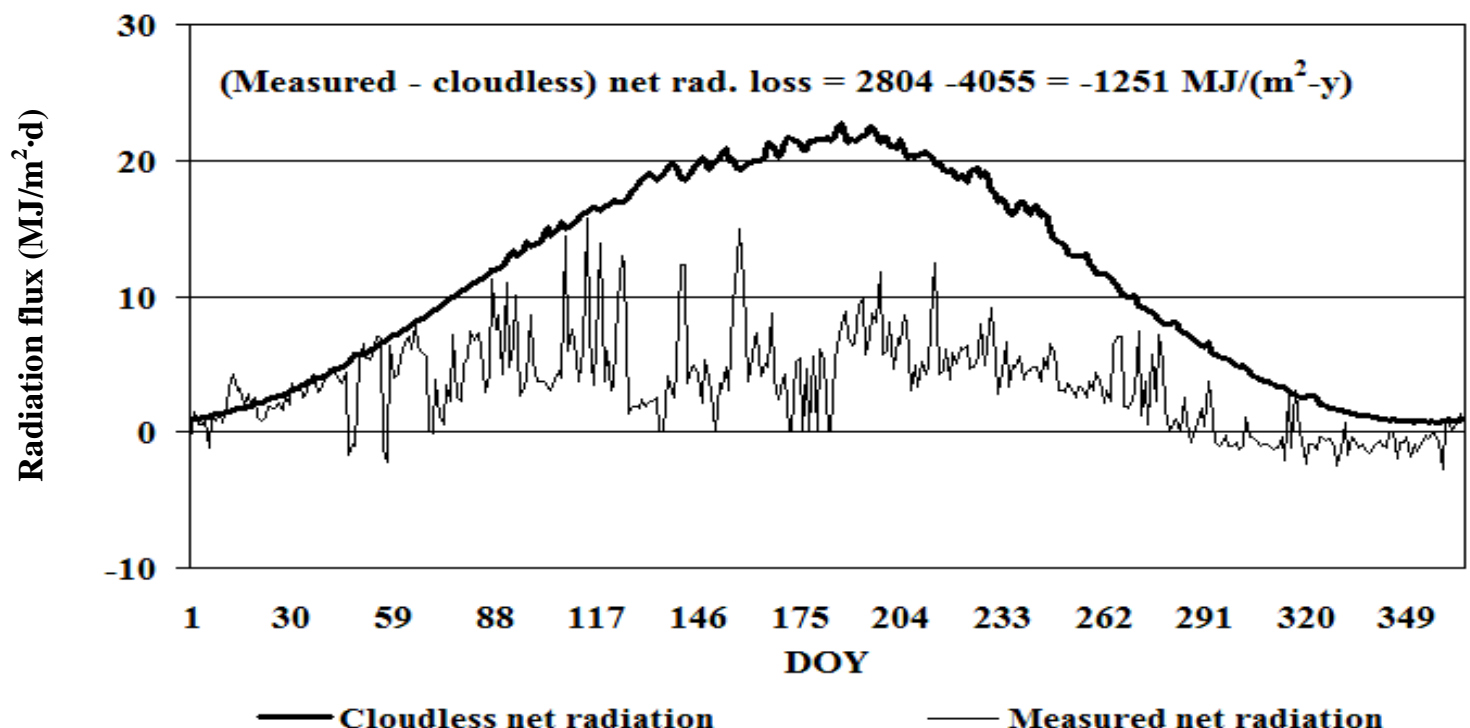

Fig. 14 The cloudless and measured available energy $\left(R_{n}\right)$ during 2007 at the experimental site in Logan, Utah, USA. 


\section{Concluding Remarks}

The effects of cloudiness on the 20-min and 24-h radiation budget components were evaluated. Both measured net shortwave $\left(\mathrm{R}_{\mathrm{si}}-\mathrm{R}_{\mathrm{so}}\right)$ and measured net longwave $\left(\mathrm{R}_{\mathrm{lo}}-\mathrm{R}_{\mathrm{li}}\right)$ were less than cloudless values during 4-5 September, 2007. This yielded less available energy during these two days. Analysis showed the same trend happened during 2007. This means cloudiness in this mountainous valley causes less energy to be available and the outcome is a negative feedback or cooling effect.

\section{Acknowledgement}

This research was fully supported by Utah State University, the Utah Agricultural Experiment Station, and Embry-Riddle Aeronautical University. The author wishes to express his thanks to all.

\section{References}

[1] Platt, C. M. R. 1989. "The Role of Cloud Microphysics in High-Cloud Feedback Effects on Climate Change." Nature 341 (October): 428-429. doi:10.1038/341428a0.

[2] Somerville, R. C. J. 1997. "Cloud-Radiation Parameterization as a Scaling Problem." Scripps Institution of Oceanography, University of California, San Diego. Accessed April 21, 2008. http:/www.agci.org/publications/EOC97/eoc97session1/S omerville.html.

[3] Wetherald, R. T., and Manabe, S. 2004. "Cloud Feedback Process in a General Circulation Model." Journal of Atmospheric Science 45 (8): 1397-1416.

[4] Soden, B. I., Broccoli A. J., and Hemler, R. S. 2004. "On the Use of Cloud Forcing to Estimate Cloud Feedback." Journal of Climate 17 (19): 3661-65.
[5] Soden, B. I. and I. M. Held. 2006. "An Assessment of Climate Feedback in Coupled-Atmosphere." Journal of Climate 17 (19): 3354-60.

[6] Sun, M. and Cess, R. D. 2004. "A Procedure for Evaluating Feedback Mechanism in Coupled Atmosphere/Ocean Climate Model.” Geophysical Research Letters 31: L12215. doi: 10.1029/2004GL019876.

[7] Zhang M. and Bretheron, C. 2008. "Mechanism of Low Cloud Climate Feedback in Idealized Singe-Column Simulations with the Community Atmospheric Model (CAM3)." Journal of Climate 21: 4859-4878. doi: 10.1175/2008JCL12237.1.

[8] Malek, E. 1997. "Evaluation of Effective Atmospheric Emissivity and Parameterization of Cloud at Local Scale." Atmospheric Research 45 (1): 41-54.

[9] Malek, E. 2007. "Cloud Contribution to the Daily and Annual Radiation Budget in a Mountainous Valley." Journal of Atmospheric Research 88 (3-4): 367-80. doi: 10.1016/2007.11.029.

[10] Allen, R. G., Walter, I. A., Elliott, R. L., Howell, T. A., Itenfisu, D., Jensen, M. E. and Snyder R. L. (Eds.). 2005. The ASCE Standardized Reference Evapotranspiration Equation. Environmental and Water Resources Institute of the American Society of Civil Engineers. Final Report, Washington, D.C..

[11] Monteith, J. L., and Unsworth, M. H. 1990. Principles of Environmental Physics. New York: Edward Arnold.

[12] Brunt, D. 1932. "Notes on Radiation from the Atmosphere." Quarterly Journal of Royal Meteorological Society 58: 389 - 418.

[13] Brutsaert, W. H. 1975. "On A Derivable Formula for Longwave Radiation from Clear Skies.” Water Resources Research 11: 742-744.

[14] Idso, S. B. 1981. "A Set of Equations for Full Spectrum and 8-14 $\mu \mathrm{m}$ and 10.5-12.5 $\mu \mathrm{m}$ Thermal Radiation from Cloudless Skies." Water Resources Research 17: 295-304.

[15] Monteith, J. L., and Unsworth, M. H. 2007. Principles of Environmental Physics. Academic Press. 